\title{
ANALISIS NILAI EKONOMI LIMBAH INDUSTRI KELAPA SAWIT DI PT. SANDABI INDAH LESTARI KABUPATEN BENGKULU UTARA)
}

\author{
The Economic Value of Oil Palm Industry Waste \\ at PT. Sandabi Indah Lestari in North Bengkulu)
}

\author{
Shofaul Afifah, Sriyoto, dan Bambang Sumantri \\ Jurusan Sosial Ekonomi Pertanian Fakultas Pertanian Universitas Bengkulu
}

\begin{abstract}
Solid and liquid waste from PT. Sandabi Indah Lestari only do the management and utilization. The Company not count the economic value of waste produced. If the company counting and know about the economic value of waste, so the company will know advantage which ought to be accepted by PT. SIL. This research aim to identify kind and form of waste, and also counting and analysis economic value of waste yielded by PT. SIL. Analysis method the use is descriptive analysis for first aim and quantitative descriptive for second aim. Based on the research result, solid waste the yielded is empty fruits bunch, fiber, shell and solid. Liquid waste consist of condensate and sludge oil. The form and benefit from each yielded waste different each other. Total economic value of waste yielded by PT. SIL is $R p$ 518.140.954,47/month. The mentioned mean that the waste of yielded by PT. SIL have economic value and than the company getting of benefit, that is the company getting income from waste is $R p$ $518.140 .954,47 /$ month.
\end{abstract}

Keywords: solid waste, liquid waste, economic value of waste

\section{PENDAHULUAN}

PT. Sandabi Indah Lestari merupakan salah satu perusahaan perkebunan kelapa sawit yang berlokasi di Kabupaten Bengkulu Utara. PT. SIL ini memiliki 3 wilayah perkebunan di Provinsi Bengkulu, yaitu wilayah perkebunan di Lubuk Banyau, Seluma dan Ketahun. Kapasitas sekali produksi dalam PMKS PT. Sandabi Indah Lestari ini adalah 45 ton/jam dan menghasilkan 120-150 ton minyak kelapa sawit per hari. Selain menghasilkan CPO dan kernel, PMKS PT. Sandabi Indah Lestari juga menghasilkan produk sampingan, yaitu limbah. Limbah padat berupa limbah janjang kosong, cangkang (shell), serabut (fiber) dan solid, sedangkan limbah cair dapat berupa minyak kotor dan condensate. Selama ini PMKS PT. Sandabi Indah Lestari hanya melakukan pengelolaan terhadap limbah dan tidak memperhitungkan nilai ekonomi yang sebenarnya ada pada setiap limbah yang dihasilkan tersebut. Jika diketahui nilai ekonomi limbah yang sesungguhnya, maka perusahaan akan mengetahui pula keuntungan yang seharusnya diperoleh 
perusahaan. Oleh karena itu, penelitian mengenai analisis nilai ekonomi ini perlu dilakukan. Berdasarkan permasalahan di atas, maka penulis tertarik untuk melakukan penelitian dengan tujuan untuk mengidentifikasi jenis dan bentuk limbah, serta menghitung dan menganalisis nilai ekonomi dari limbah industri (limbah padat dan limbah cair) yang dihasilkan PMKS PT. Sandabi Indah Lestari.

\section{METODE PENELITIAN}

\section{Waktu dan Lokasi Penelitian}

Penelitian ini dilaksanakan di PMKS PT. Sandabi Indah Lestari yang terletak di Desa Lubuk Banyau, Kecamatan Padang Jaya, Kabupaten Bengkulu Utara dan penelitian ini dilaksanakan pada bulan Februari 2016.

\section{Jenis dan Sumber Data}

Data yang digunakan dalam penelitian ini adalah data primer dan data sekunder. Data primer berupa data jenis-jenis limbah, bentuk limbah, dan harga limbah yang dihasilkan PMKS PT. Sandabi Indah Lestari. Data sekunder berupa data jumlah limbah dan biaya-biaya bulan Desember 2015.

\section{Metode Analisis Data}

\section{Analisis Guna Mengidentifikasi Jenis dan Bentuk Limbah}

Metode analisis yang digunakan untuk mengetahui jenis dan bentuk limbah industri di PT. Sandabi Indah Lestari adalah dengan menggunakan analisis deskriptif. Data yang diperoleh dianalisis dengan cara dideskripsikan sesuai dengan data yang telah terkumpul dan keadaan di lapangan. Menurut Sugiyono (2008), analisis deskriptif merupakan analisis yang bertujuan untuk menjabarkan suatu fenomena yang terjadi saat ini dengan menggunakan prosedur ilmiah untuk menjawab masalah secara aktual.

\section{Analisis Nilai Ekonomi Limbah}

Metode analisis yang digunakan adalah analisis deskriptif kuantitaf. Perhitungan nilai ekonomi dianalisis dengan menggunakan analisis ekonomi dan kemudian dideskripsikan sesuai hasil yang diperoleh. Menurut Arsyad (2000), untuk memahami optimisasi ekonomi dapat dengan menelaah beberapa bentuk hubungan fungsional, yaitu dengan memperhatikan hubungan antara jumlah produk yang terjual $(\mathrm{Q})$ dengan harga jual $(\mathrm{P})$, di mana:

$$
\begin{array}{lll}
\mathrm{TR}=\mathrm{P} \times \mathrm{Q} & & \\
\text { Keterangan: } & \mathrm{P} & =\text { Harga tiap unit yang terjual }(\mathrm{Rp} / \mathrm{kg}) \\
& \mathrm{Q} & =\text { Jumlah unit }(\mathrm{kg} / \text { bulan }) \\
& \mathrm{TR} & =\text { Total penerimaan }(\mathrm{Rp} / \mathrm{bulan})
\end{array}
$$


Jika nilai ekonomi dianalisis dengan pendekatan nilai pendapatan dari hasil menjual limbah ke pasaran bebas ataupun memanfaatkan limbah, maka secara matematis nilai ekonomi tersebut dapat ditulis sebagai berikut (Sunyoto, 2013):

$$
\begin{array}{lll}
\mathrm{I}=\mathrm{TR}-\mathrm{TC} & & \\
\text { Keterangan: } & \mathrm{I} & =\text { Pendapatan }(\mathrm{Rp} / \text { bulan }) \\
& \mathrm{TR} & =\text { Total penerimaan }(\mathrm{Rp} / \mathrm{bulan}) \\
& \mathrm{TC} & =\text { Total biaya }(\mathrm{Rp} / \mathrm{bulan})
\end{array}
$$

Untuk memperoleh nilai ekonomi (nilai ekonomi total), komponen ekonomi total yang dihitung adalah nilai guna langsung dan nilai guna tidak langsung.

Nilai guna langsung (N1)

Nilai guna langsung digunakan untuk menghitung nilai ekonomi limbah yang dijual. Limbah yang dijual berupa limbah cair dan juga limbah padat, dihitung dengan menggunakan persamaan:

$$
\begin{array}{lcl}
\mathrm{N}=(\mathrm{P} \times \mathrm{Q})-\mathrm{TC} & \\
\text { Keterangan: } & \mathrm{N} & =\text { Nilai limbah cair } / \text { padat }(\mathrm{Rp} / \mathrm{bulan}) \\
\mathrm{P} & =\text { Harga limbah cair } / \text { padat }(\mathrm{Rp} / \mathrm{kg}) \\
\mathrm{Q} & =\text { Produksi limbah }(\mathrm{kg} / \text { bulan }) \\
\mathrm{TC} & =\text { Biaya total }(\mathrm{Rp} / \mathrm{bulan})
\end{array}
$$

Nilai guna tidak langsung (N2)

Nilai guna tidak langsung, digunakan untuk menghitung nilai ekonomi limbah yang dimanfaatkan (tidak dijual), limbah yang dimanfaatkan berupa limbah padat dan dapat dihitung dengan persamaan:

$$
\begin{array}{lll}
\mathrm{N}=(\mathrm{Q} \times \mathrm{P})-\mathrm{TC} & \\
\text { Keterangan: } & \mathrm{Q} & =\text { Jumlah limbah }(\mathrm{kg} / \text { bulan }) \\
& \mathrm{P} & =\text { Harga jual }(\mathrm{Rp} / \mathrm{kg}) \\
& \mathrm{TC} & =\text { Biaya total }(\mathrm{Rp} / \mathrm{bulan})
\end{array}
$$

Berdasarkan persamaan-persamaan di atas, maka nilai ekonomi total (NET) dapat dihitung dengan rumus:

NET = SNilai Guna Langsung + ENilai Guna Tidak langsung

Keterangan: harga jual limbah yang dimanfaatkan diasumsikan sama dengan harga jual limbah yang dijual. 


\section{HASIL DAN PEMBAHASAN}

\section{Jenis dan Bentuk Limbah}

Limbah industri yang dihasilkan pabrik minyak kelapa sawit cukup banyak jumlahnya dan akan terus meningkat seiring dengan meningkatnya kapasitas produksi. Berdasarkan pengolahan tandan buah segar menjadi CPO yang dilakukan PT. Sandabi Indah Lestari, dihasilkan limbah, yaitu limbah padat, limbah cair dan polutan. Limbah padat terdiri dari janjang kosong, serabut, cangkang dan juga solid, sedangkan untuk limbah cair terdiri dari sludge oil (minyak kotor) dan condensate hasil rebusan. Pada perusahaan perkebunan lainnya, yaitu PT. Agricinal, terjadi perbedaan limbah padat yang dihasilkan PT. Agricinal dalam mengolah TBS menjadi CPO dan PKO menghasilkan limbah padat berupa limbah tandan kosong/janjang kosong, cangkang, serabut, solid dan bungkil (Doli, 2015). Limbah padat bungkil tidak dihasilkan diseluruh perusahaan perkebunan kelapa sawit. Untuk menghasilkan limbah bungkil alat yang digunakan merupakan alat khusus pengolahan kernel menjadi PKO (palm kernel oil) dan alat tersebut tidak termasuk ke dalam alat pengolah TBS menjadi CPO.

\section{Janjang Kosong}

Limbah janjang kosong merupakan limbah padat terbanyak yang dihasilkan dari pengolahan tandan buah segar menjadi CPO. Janjang kosong dihasilkan setelah proses pada thresser. Untuk setiap ton tandan buah segar yang diolah, maka akan dihasilkan limbah janjang kosong rata-rata sebanyak 22\%. Di PT. Sandabi Indah Lestari, seluruh janjang kosong yang dihasilkan tersebut dimanfaatkan. Janjang kosong dimanfaatkan sebagai bahan baku pembuatan kompos dan abu janjang. Janjang kosong yang dimanfaatkan untuk kompos dan abu janjang, akhir dari pengolahannya digunakan sebagai pupuk. Janjang kosong yang dimanfaatkan menjadi kompos, diolah bersama dengan bahan tambahan, yaitu solid. Menurut Sarwono (2008) dalam penelitiannya, limbah janjang kosong bersifat organik, sehingga janjang kosong dapat dimanfaatkan sebagai pupuk dengan mengaplikasikan limbah tersebut di atas tanah di sekitar tanaman sawit.

\section{Serabut}

Serabut kelapa sawit (fiber) yang dihasilkan dari total pengolahan tandan buah segar adalah sebanyak 3\%. Serabut dihasilkan pada depericarper station. Serabut di PT. Sandabi Indah Lestari digunakan untuk bahan bakar boiler. Adanya pembakaran di dalam boiler akan menghasilkan uap yang akan digunakan sebagai pembangkit listrik. Listrik tersebut digunakan baik untuk kebutuhan pabrik maupun perumahan karyawan dan staf disekitar pabrik. Menurut Harris et al (2013), serabut kelapa sawit dapat dimanfaatkan sebagai sumber energi alternatif pada PLTU. Serabut dimanfaatkan sebagai bahan bakar pada PLTU 6 MW, dimana digunakan untuk memanaskan air di dalam boiler sehingga menghasilkan temperatur dan tekanan uap yang mampu 
memutar turbin uap. Pada saat menggunakan bahan bakar serabut PLTU 6 MW menghasilkan output rata - rata 2,3 $\mathrm{MW} / \mathrm{hr}$ dan dalam $1 \mathrm{MW}$ output membutuhkan 1,83 ton serabut.

\section{Cangkang}

Limbah cangkang dihasilkan setelah melewati beberapa proses pemisahan di beberapa alat pada stasiun kernel/kernel plant. Cangkang dapat dikatakan sebagai tempurung kelapa sawit. Dari tandan buah segar yang diolah, akan dihasilkan cangkang sebanyak 6\%. Di PMKS PT. Sandabi Indah Lestari, cangkang yang dihasilkan tersebut, hanya $2 \%$ yang digunakan sebagai bahan baku boiler, sedangkan sebanyak $98 \%$ limbah cangkang dijual kepada pembeli. Pada awal beroperasinya PMKS PT. Sandabi Indah Lestari, yaitu sekitar tahun 2011, limbah cangkang pernah dimanfaatkan sebagai bahan penimbun jalan untuk akses ke PMKS dan sekitarnya. Menurut Suhartana (2006), limbah cangkang dapat dimanfaatkan sebagai bahan baku pembuatan arang aktif, dimana kandungan kimia yang terkandung dalam arang aktif (senyawa karbon) dapat digunakan untuk proses penjernihan air. Selain itu menurut Kurniati (2008), arang aktif juga dapat digunakan dalam proses pemurnian gas yang meliputi desulfurisasi dan menghilangkan gas racun, digunakan dalam pengolahan LNG yang meliputi desulfurisasi dan penyaringan bahan mentah, serta dapat digunakan sebagai katalisator (pengangkut vinil klorida dan vinil asetat).

\section{Solid}

Solid merupakan limbah padat yang terbentuk saat proses penyaringan kasar di clarifikasi station. Solid memiliki bentuk dan konsistensi seperti ampas tahu, berwarna kecokelatan dan masih mengandung CPO (Crude Palm Oil) sekitar 1,5\%. PT. Sandabi Indah Lestari hanya memanfaatkan limbah solid sebagai bahan baku pembuatan kompos. Di Kabupaten Kotawaringin Barat Provinsi Kalimantan Tengah, limbah solid dimanfaatkan sebagai bahan pakan ternak, khususnya ternak sapi. Di Provinsi Kalimantan Tengah, ketersediaan limbah solid sangat melimpah karena di daerah tersebut terdapat pabrik minyak kelapa sawit. Limbah solid mengandung beberapa unsur, yakni protein kasar, serat kasar, lemak, kalsium, fosfor serta energi sehingga limbah solid baik untuk pertumbuhan ternak sapi (Widjaja et al, 2002).

Berdasarkan hasil penelitian Azmi dan Gunawan (2005), komposisi pakan pelepah sawit 55\%, rumput lapangan 30\%, dan lumpur sawit/solid sebesar $15 \%$ merupakan pakan alternatif cukup baik untuk sapi potong penggemukan. Pertambahan bobot hidup harian rata-rata (average daily gain/ADG) 226,66 gram per ekor dan jumlah konsumsi pakan sebesar 8,85 kg per ekor. 


\section{Limbah Cair}

Limbah cair yang dihasilkan yaitu sekitar 45\% sampai dengan 50\%, berupa condensate dan sludge oil. Limbah cair condensate dihasilkan lebih banyak dibandingkan limbah cair sludge oil. Limbah cair Condensate dihasilkan pada stasiun sterilizer, yaitu setelah perebusan tandan buah segar dilaksanakan. Sludge oil dengan nama lain minyak kotor diperoleh setelah melalui proses klarifikasi di stasiun klarifikasi. Sludge oil merupakan limbah cair yang memiliki bentuk menyerupai agar-agar dan berwarna kehitaman. Sludge oil adalah salah satu jenis limbah yang dipasarkan oleh PT. Sandabi Indah Lestari ke perusahan-perusahaan kosmetik dan biasanya digunakan untuk bahan baku sabun, kosmetik dan sejenisnya. Pada penelitian lainnya, dikatakan bahwa Limbah cair pabrik minyak kelapa sawit memiliki nilai nutrisi yang baik dimana berpotensi digunakan sebagai pupuk organik cair. Aplikasi limbah cair tersebut mamapu meningkatkan unsur hara $\mathrm{P}, \mathrm{Ca}, \mathrm{Mg}$ dan K. Limbah cair dengan BOD rendah, tidak dapat meningkatkan TBS tanpa melalui pengontrolan (Budianta, 2004).

Pemanfaatan limbah cair sebagai pupuk/bahan pembenah tanah di perkebunan kelapa sawit sangat dimungkinkan atas dasar adanya kandungan hara dalam limbah tersebut. Pemanfaatan limbah ini di samping sebagai sumber pupuk/bahan organik juga akan mengurangi biaya pengolahan limbah sebesar 50-60\% (Nur, 2013).

\section{Limbah Polutan}

Polutan dapat menyebabkan pencemaran pada udara, daratan maupun pada air, dengan kata lain polutan merupakan penyebab terjadinya polusi. Zat/benda dapat disebut polutan jika keberadaannya dapat menyebabkan kerugian terhadap makhluk hidup. Di PT. Sandabi Indah Lestari, limbah yang termasuk ke dalam polutan adalah limbah bahan berbahaya dan beracun, dapat berupa padat, cair maupun gas. Polutan padat dapat berupa kaleng, logam, plastik, besi dan sebagainya. Polutan cair berupa oli, detergen, dan sebagainya, sedangkan polutan gas berupa karbon dioksida, karbon monoksida, metana dan Iain-Iain. Untuk polutan berupa cair dan padat bukan merupakan hasil dari pengolahan TBS menjadi CPO/pemanfaatan limbah, namun dari bahan-bahan pendukung dalam menjalankan proses produksi, seperti kaleng/tempat oli, dsb. Zat-zat pencemar yang ada di udara (gas) umumnya berupa debu, asap dan gas buangan hasil pembakaran. Asap yang dihasilkan dapat bersumber dari cerobong boiler, cerobong genset dan gas dari reaksi kimia di laboratorium pabrik. Untuk gas merupakan polutan yang dihasilkan dari proses pengolahan TBS menjadi CPO. Gas yang dihasilkan tersebut dapat berbahaya bagi kesehatan manusia/makhluk hidup. 


\section{Analisis Nilai Ekonomi Limbah Industri PT. Sandabi Indah Lestari}

Nilai ekonomi limbah industri kelapa sawit merupakan nilai yang dimiliki oleh limbah pabrik minyak kelapa sawit. Nilai limbah yang dijual termasuk ke dalam nilai guna langsung, sedangkan nilai limbah yang dimanfaatkan termasuk ke dalam nilai guna tidak langsung.

Komponen Biaya Pemanfaatan Limbah PT. Sandabi Indah Lestari Biaya Tetap

Tabel 1. Biaya Penyusutan Alat Produksi Limbah PT. Sandabi Indah Lestari

\begin{tabular}{llr}
\hline \multicolumn{1}{c}{ Jenis Limbah } & \multicolumn{1}{c}{ Jenis Peralatan } & Penyusutan (Rp/bln) \\
\hline Janjang kosong & EFB Hopper & 4.000 .000 \\
& EFB Conveyor & 580.000 \\
& Shredder & 4.333 .333 \\
& Dumptruck & 1.960 .000 \\
& Loader & 1.764 .333 \\
\hline Jumlah & & 12.637 .667 \\
\hline Serabut (fiber) & Fiber shell conveyor & 159.360 \\
& Fuel Return Elevator & 293.333 \\
& Fuel Distibuting Conveyor & 446.667 \\
\hline Jumlah & & 899.360 \\
\hline Cangkang & Fiber shell conveyor & 6.640 \\
& Loader & 469.000 \\
\hline Jumlah & & 475.640 \\
\hline Solid & Solid bin & 526.667 \\
& Dumptruck & 373.333 \\
\hline Jumlah & & 900.000 \\
\hline Sludge oil & Sludge collection pit & 163.333 \\
& Daily pond & 216.667 \\
\hline Jumlah & Cooling pond & 200.000 \\
\hline
\end{tabular}

Sumber: Data Sekunder Diolah (2015)

Biaya tetap (fixed cost) merupakan biaya yang tidak habis digunakan dalam satu periode produksi (Hermanto disitir dari Wulandari, 2011). Biaya tetap terdiri dari biaya penyusutan alat, biaya pemeliharaan kendaraan pengangkutan, biaya tenaga kerja dan biaya pajak penjualan. Biaya penyusutan alat yang digunakan dalam produksi limbah di PT. Sandabi Indah Lestari disajikan pada Tabel 1. Untuk biaya pajak penjualan yang dibebankan adalah sebesar $10 \%$ untuk limbah yang dijual, sedangkan untuk limbah yang dimanfaatkan tidak dibebankan biaya pajak penjualan. 
Tabel 2. Biaya Pemeliharaan Alat dalam Menghasilkan Limbah pada PT. Sandabi Indah Lestari

\begin{tabular}{|c|c|c|c|c|c|c|}
\hline \multicolumn{3}{|c|}{ Biaya } & \multicolumn{3}{|c|}{ Fiber } & Sludge \\
\hline Nama & $\begin{array}{l}\text { Pemeliharaan } \\
\text { (Rp/bln) }\end{array}$ & $\begin{array}{r}\text { Biaya JJK } \\
\text { (Rp/bln) }\end{array}$ & $\begin{array}{l}\text { Biaya Solid } \\
\text { (Rp/bln) }\end{array}$ & $\begin{array}{c}(\mathrm{Rp} \\
\text { /bln })\end{array}$ & $\begin{array}{l}\text { Cangkang } \\
\text { (Rp/bln) }\end{array}$ & $\begin{array}{l}\text { Oil(Rp } \\
\text { /bln) }\end{array}$ \\
\hline Dumptruck & 3.200 .000 & 2.688 .000 & 512.000 & - & - & - \\
\hline Jumlah & 3.200 .000 & 2.688 .000 & 512.000 & & & \\
\hline
\end{tabular}

Sumber: Data Sekunder Diolah (2015)

Sementara itu biaya pemeliharaan yang dikeluarkan perusahaan dalam memproduksi limbah yang tersaji pada Tabel 2. Biaya pemeliharaan yang dibebankan untuk setiap masing-masing limbah sesuai dengan penggunaannya. Penggunaan dumptruck digunakan bersama, oleh karena itu terjadi joint cost. Dumptruk digunakan pada pengangkutan janjang kosong dan solid. Masing-masing penggunaannya yaitu $84 \%$ untuk pengangkutan janjang kosong dan $16 \%$ untuk pengangkutan solid. Selanjutnya, biaya tenaga kerja dalam menangani limbah disajikan pada Tabel 3.

Biaya tenaga kerja terdiri dari tenaga kerja pabrik dan tenaga kerja pengemudi dumptruck. Tenaga kerja pabrik terdiri dari pekerja 2 shift yaitu shift siang dan shift malam, yang bertanggung jawab atas limbah yang dihasilkan. Pekerja 2 shift berlaku untuk masing-masing limbah. Kemudian, biaya tenaga kerja pengemudi dumptruck dibebankan pada limbah janjang kosong dan solid, karena dumptruck digunakan untuk mengangkut kedua jenis limbah tersebut. Biaya tenaga kerja yang dibebankan sebesar $84 \%$ pada limbah janjang kosong dan 16\% pada limbah solid. Loader digunakan pada pengangkutan janjang kosong dan cangkang. Pada limbah janjang kosong dan cangkang, masing-masing adalah sebesar $79 \%$ dan $21 \%$.

Biaya tenaga kerja terdiri dari tenaga kerja pabrik dan tenaga kerja pengemudi dumptruck. Tenaga kerja pabrik terdiri dari pekerja 2 shift yaitu shift siang dan shift malam, yang bertanggung jawab atas limbah yang dihasilkan. Pekerja 2 shift berlaku untuk masing-masing limbah. Kemudian, biaya tenaga kerja pengemudi dumptruck dibebankan pada limbah janjang kosong dan solid, karena dumptruck digunakan untuk mengangkut kedua jenis limbah tersebut. Biaya tenaga kerja yang dibebankan sebesar $84 \%$ pada limbah janjang kosong dan 16\% pada limbah solid. Loader digunakan pada pengangkutan janjang kosong dan cangkang. Pada limbah janjang kosong dan cangkang, masing-masing adalah sebesar $79 \%$ dan $21 \%$.

Total biaya tetap untuk limbah janjang kosong lebih tinggi dibandingkan total biaya tetap limbah lainnya. Hal tersebut disebabkan jumlah alat dan tenaga kerja yang digunakan dalam memproduksi limbah janjang kosong cukup banyak, serta beban biaya pemeliharaan kendaraan yang tinggi. Total biaya tetap dari seluruh limbah diperoleh sebesar Rp 41.943.867/bulan dan total biaya tetap limbah memberikan pengaruh sebesar $42,8 \%$ terhadap total biaya yang digunakan dalam memproduksi limbah. Total biaya tetap lebih

196 | Shofaul Afifah, Sriyoto, dan Bambang S., Analisis Nilai Ekonomi Limbah... 
rendah dari pada total biaya variabel disebabkan karena pembebanan biaya dimulai ketika limbah telah terbentuk dan tanpa menggunakan joint cost bersama produk utama sehingga biaya yang termasuk ke dalam komponen biaya tetap jumlahnya sedikit.

\section{Tabel 3. Biaya Tenaga Kerja dalam Menangani Limbah pada PT. Sandabi} Indah Lestari

\begin{tabular}{cccrr}
\hline Jenis limbah & $\begin{array}{c}\text { Jumlah } \\
\text { Tenaga } \\
\text { Kerja }\end{array}$ & $\begin{array}{c}\text { Jumlah Hari } \\
\text { Kerja (HOK) }\end{array}$ & $\begin{array}{c}\text { Upah Tenaga } \\
\text { Kerja } \\
\text { (Rp/bulan) }\end{array}$ & \multicolumn{1}{c}{$\begin{array}{c}\text { Biaya } \\
\text { (Rp/bulan) }\end{array}$} \\
\hline Janjang Kosong & 2 & 26 & 3.321 .600 & 3.321 .600 \\
& 2 & 26 & 3.321 .600 & 2.790 .144 \\
& 2 & 26 & 3.321 .600 & 2.624 .064 \\
\hline Serabut & 2 & 26 & 3.321 .600 & 3.321 .600 \\
\hline Cangkang & 2 & 26 & 3.321 .600 & 3.321 .600 \\
& 2 & 26 & 3.321 .600 & 697.536 \\
\hline Solid & 2 & 26 & 3.321 .600 & 3.321 .600 \\
& 2 & 26 & 3.321 .600 & 531.456 \\
\hline Sludge Oil & 2 & 26 & 3.321 .600 & 3.321 .600 \\
& 1 & 26 & 1.660 .800 & 1.660 .800 \\
\hline
\end{tabular}

Sumber: Data Sekunder Diolah (2015)

Biaya Variabel

Biaya variabel merupakan biaya yang tergantung pada tinggi rendahnya produksi yang dihasilkan. Biaya variabel dalam produksi limbah di PT. Sandabi Indah Lestari disajikan pada Tabel 4.

Tabel 4. Biaya Variabel dalam Produksi Limbah pada PT. Sandabi Indah Lestari

\begin{tabular}{lccrcrr}
\hline \multicolumn{1}{c}{$\begin{array}{c}\text { Jenis } \\
\text { Penggunaan }\end{array}$} & $\begin{array}{c}\text { Biaya } \\
(\mathrm{Rp} / \mathrm{bln})\end{array}$ & $\begin{array}{c}\text { Biaya JJK } \\
(\mathrm{Rp} / \mathrm{bln})\end{array}$ & $\begin{array}{c}\text { Serabut } \\
(\mathrm{Rp} / \mathrm{bln})\end{array}$ & $\begin{array}{c}\text { Biaya } \\
\text { Cangkang } \\
(\mathrm{Rp} / \mathrm{bln})\end{array}$ & $\begin{array}{c}\text { Biaya Solid } \\
(\mathrm{Rp} / \mathrm{bln})\end{array}$ & $\begin{array}{c}\text { Sludge } \\
\text { Oil } \\
(\mathrm{Rp} / \mathrm{bln})\end{array}$ \\
\hline $\begin{array}{l}\text { Solar Loader } \\
\text { Pelumas }\end{array}$ & $40.778 .906,5$ & $32.215 .336,14$ & - & $8.563 .570,3$ & & - \\
$\begin{array}{l}\text { Loader } \\
\text { Solar }\end{array}$ & 2.918 .200 & 2.305 .378 & - & 612.822 & & - \\
Dumptruck & 12.200 .000 & 10.248 .000 & - & - & 1.952 .000 & - \\
\hline \multicolumn{1}{l}{ Jumlah } & & $55.897 .106,5$ & - & $9.176 .392,3$ & 1.952 .000 & - \\
\hline
\end{tabular}

Sumber: Data Sekunder Diolah (2015)

Solar dan pelumas untuk loader dibebankan pada limbah janjang kosong dan cangkang yang dijual, masing-masing penggunaannya adalah sebesar $79 \%$ dan $21 \%$, sesuai dengan total limbah yang menggunakan loader. Total biaya variabel memberikan pengaruh sebesar 57,2 \% dari total biaya yang digunakan. Total biaya variabel diperoleh lebih tinggi dibandingkan total biaya tetap karena biaya yang harus dikeluarkan pada biaya operasional cukup tinggi, seperti biaya penggunaan solar. Solar yang digunakan dalam 
mengoperasikan alat berat digunakan cukup banyak, sehingga biaya yang dibebankan juga tinggi.

\section{Produksi dan Penerimaan Limbah PT. Sandabi Indah Lestari}

PT. Sandabi Indah Lestari menghasilkan limbah padat dan limbah cair di setiap proses produksinya. Limbah padat janjang kosong dihasilkan sekitar $22 \%$ dari total TBS yang diolah, cangkang $6 \%$, serabut $3 \%$, solid $4 \%$ dan sludge oil 0,2\%. Selama bulan Desember, PT. Sandabi Indah Lestari menghasilkan limbah padat dan sludge oil serta penerimaan seperti tersaji dalam Tabel 5.

\begin{tabular}{|c|c|c|c|}
\hline \multicolumn{4}{|c|}{ Penerimaan limbah yang dijual } \\
\hline Jenis Limbah & $\begin{array}{c}\text { Jumlah Limbah } \\
\text { (kg/bln) }\end{array}$ & $\begin{array}{c}\text { Harga } \\
\text { Jual }(\mathrm{Rp} / \mathrm{kg})\end{array}$ & $\begin{array}{l}\text { Penerimaan } \\
\text { (Rp/bln) }\end{array}$ \\
\hline Cangkang & 798.665 & 500 & 399.332 .500 \\
\hline Sludge oil & 28.586 & 300 & 8.575 .800 \\
\hline Jumlah & & & 407.908 .300 \\
\hline \multicolumn{4}{|c|}{ Penerimaan limbah tidak dijual/dimanfaatkan } \\
\hline Janjang kosong & 3.091 .243 & 50 & 154.562 .155 \\
\hline Serabut & 421.533 & 165 & 69.552 .970 \\
\hline Cangkang & 16.229 & 500 & 8.114 .500 \\
\hline Solid & 590.146 & 25 & 14.753 .660 \\
\hline Jumlah & & & 246.983 .285 \\
\hline Total penerimaan & & & 654.891 .585 \\
\hline
\end{tabular}

Sumber: Data Sekunder Diolah (2015)

Penerimaan dari limbah yang dijual lebih tinggi dari pada limbah yang dimanfaatkan karena dipengaruhi oleh perbedaan harga jual limbah serta volume limbah yang dihasilkan. Harga cangkang dan sludge oil lebih tinggi dibandingkan dengan limbah janjang kosong, solid dan serabut. Hal tersebut mempengaruhi tingginya penerimaan yang diperoleh. Meskipun jumlah limbah cangkang tidak sebanyak limbah janjang kosong, namun penerimaan yang berasal dari limbah cangkang lebih besar dari pada penerimaan yang berasal dari limbah janjang kosong. Limbah cangkang menjadi sumber penerimaan tertinggi karena dipengaruhi oleh harga jual yang cukup tinggi.

Sebanyak 37,7\% merupakan penerimaan dari limbah yang dimanfaatkan. Penerimaan limbah dimanfaatkan jauh lebih rendah dibandingkan dengan limbah yang dijual. Harga dan jumlah limbah dihasilkan mempengaruhi rendahnya penerimaan. Sebagai contoh, meskipun jumlah limbah yang dihasilkan pada limbah janjang kosong tertinggi dibandingkan dengan keseluruhan limbah, namun janjang kosong tidak menjadi sumber penerimaan yang tinggi karena harga jual janjang kosong sangat murah. Kemudian, limbah cangkang yang dimanfaatkan harga jualnya 
sama dengan limbah cangkang yang dijual namun jumlahnya berbeda, oleh sebab itu penerimaannya juga rendah.

\section{Nilai Ekonomi Total Limbah Industri Kelapa Sawit}

Nilai ekonomi total diperoleh dari penjumlahan nilai guna langsung dan tidak langsung. Nilai guna langsung dan tidak langsung didapatkan dari perkalian antara jumlah limbah yang dihasilkan dengan harga limbah dan dikurangkan dengan total biaya produksi (fixed cost dan variable cost) limbah yang dijual. Namun, perbedaannya yaitu nilai guna tidak langsung merupakan nilai yang diperoleh dari limbah yang dimanfaatkan/tidak dijual. Pada Tabel 6 merupakan nilai guna langsung, nilai guna tidak langsung, dan total nilai ekonomi limbah yang dihasilkan PMKS PT. Sandabi Indah Lestari pada bulan Desember 2015.

Tabel 6. Nilai Ekonomi Limbah Industri Kelapa Sawit PT. Sandabi Indah Lestari

\begin{tabular}{lrrrr}
\hline \multicolumn{5}{c}{ Nilai guna langsung } \\
\hline Jenis Limbah & $\begin{array}{c}\text { Penerimaan } \\
(\mathrm{Rp} / \mathrm{bln})\end{array}$ & Total Cost (Rp) & $\begin{array}{c}\text { Pajak } \\
\text { Penjualan }\end{array}$ & $\begin{array}{c}\text { Nilai Ekonomi } \\
(\mathrm{Rp} / \mathrm{bln})\end{array}$ \\
\hline Cangkang & 399.332 .500 & $13.249 .328,37$ & $10 \%$ & $347.474 .854,47$ \\
Sludge oil & 8.575 .800 & 5.562 .400 & $10 \%$ & 2.712 .060 \\
\hline Jumlah & 407.908 .300 & 18.029 .245 & $350.186 .914,47$ \\
\hline \multicolumn{5}{c}{ Nilai guna tidak langsung } \\
\hline Janjang & 154.562 .155 & 67.518 .157 & - & 87.043 .998 \\
kosong & 69.552 .970 & 4.220 .960 & - & 65.332 .010 \\
Serabut & 8.114 .500 & 73.072 & - & 8.041 .428 \\
Cangkang & 14.753 .660 & 7.217 .056 & - & 7.536 .604 \\
Solid & 246.983 .285 & 79.029 .245 & 167.954 .040 \\
\hline Jumlah & \multicolumn{5}{c}{$518.140 .954,47$} \\
\hline NET & \multicolumn{5}{c}{} \\
\hline
\end{tabular}

Sumber: Data Sekunder Diolah (2015)

Berdasarkan perhitungan pada Tabel 6, diperoleh nilai guna langsung dari kedua limbah yang dijual sebesar Rp 350.186.914,47/bulan. Nilai tersebut diperoleh setelah pendapatan masing-masing limbah dikurangi dengan pajak penjualan sebesar $10 \%$. Berdasarkan nilai guna langsung yang diperoleh maka perusahaan memperoleh pendapatan yang secara langsung dapat dinikmati sebesar Rp 350.186.914,47/bulan. Pada nilai guna langsung, perusahaan memperoleh cash money dari penjualan limbah, sehingga dapat langsung dinikmati oleh pihak perusahaan. Nilai guna langsung bersifat nyata bagi perusahaan. Dari nilai guna langsung, limbah yang menjadi sumber nilai terbesar adalah limbah cangkang. Limbah cangkang menjadi sumber nilai tertinggi karena kuantitas limbah dan harga jual yang cukup tinggi. Permintaan limbah cangkang cukup tinggi, hal tersebut merupakan salah satu penyebab tingginya harga jual cangkang di PT. Sandabi Indah Lestari. 
Nilai guna tidak langsung yang berasal dari limbah yang dimanfaatkan diperoleh sebesar Rp 167.954.040/bulan. Pada nilai guna tidak langsung, perusahaan tidak memperoleh cash money tetapi akan memperoleh manfaat tidak langsung dari limbah tersebut. Limbah janjang kosong merupakan limbah yang menjadi sumber nilai guna tidak langsung tertinggi. Limbah janjang kosong menjadi sumber nilai tertinggi karena kuantitas limbah yang dihasilkan sangat tinggi dibandingkan dengan limbah yang lainnya, meskipun harga jualnya cukup rendah. Sementara itu cangkang menjadi sumber nilai guna tidak langsung terendah, karena limbah cangkang yang dimanfaatkan hanya $2 \%$ dari total dihasilkan.

Berdasarkan perhitungan pada Tabel 6, dapat diketahui bahwa nilai ekonomi total (NET) sebesar Rp 518.140.954,47/bulan. Sebesar 67,6\% nilai ekonomi dipengaruhi oleh nilai guna langsung. Nilai guna langsung diperoleh lebih tinggi dibandingkan dengan nilai guna tidak langsung karena penerimaan yang diperoleh pada limbah yang dijual lebih tinggi. Selain itu total biaya untuk limbah yang dijual lebih rendah dibandingkan dengan total biaya yang digunakan pada limbah yang dimanfaatkan. Sedangkan nilai guna tidak langsung hanya memberikan pengaruh sebesar 32,4\% terhadap nilai ekonomi total limbah.

Pengelolaan limbah industri yang dilakukan PT. Sandabi Indah Lestari membawa manfaat bagi perusahaan dan bagi pekerja. Pengelolaan limbah, baik dalam penjualan maupun pemanfaatan limbah dapat menyerap tenaga kerja. Pengangguran atau tuna karya dapat dikurangi, pekerja dalam pengelolaan limbah dapat memperoleh upah dan perusahaan juga memperoleh pendapatan di luar dari pendapatan yang diperoleh dari produk utama yaitu CPO.

\section{SIMPULAN DAN SARAN}

\section{Simpulan}

Berdasarkan hasil penelitian dan pembahasan, dapat disimpulkan bahwa:

1. Limbah yang dihasilkan di PT. Sandabi Indah Lestari memiliki jenis dan bentuk yang berbeda yaitu limbah padat, limbah cair dan polutan. Limbah padat terdiri dari limbah janjang kosong, serabut, cangkang dan solid. Limbah cair terdiri dari sludge oil dan condensate, sedangkan polutan dapat berupa padat, cair dan uap.

2. Nilai guna langsung yang diperoleh dari penjualan limbah adalah sebesar Rp350.186.914,47/bulan, sedangkan nilai guna tidak langsung sebesar Rp167.954.040/bulan, sehingga diperoleh nilai ekonomi total sebesar Rp518.140.954,47/bulan. 


\section{Saran}

Dari hasil penelitian dapat direkomendasikan beberapa saran yang dapat menjadi alternatif bagi perusahaan untuk bisa diterapkan, diantaranya:

1. Perusahaan sebaiknya dapat memanfaatkan masing-masing jenis limbah kelapa sawit sesuai dengan kegunaannya agar mampu mengurangi biaya pengolahan limbah.

2. Perusahaan sebaiknya tidak hanya menganggap pendapatan/nilai ekonomi dari limbah sebagai bonus, tetapi benar-benar memperhitungkan nilai ekonomi yang ada pada limbah karena proses yang dilalui melibatkan biaya yang tidak sedikit.

\section{DAFTAR PUSTAKA}

Arsyad, Lincolin. 2000. Ekonomi Manajerial: Ekonomi Mikro terapan untuk Manajemen Bisnis. BPFE-Yogyakarta. Yogyakarta.

Azmi dan Gunawan. 2005. Pemanfaatan Pelepah Kelapa Sawit dan Solid untuk Pakan Sapi Potong. Seminar Nasional Teknologi Peternakan dan Veteriner. Bengkulu: Balai Pengkajian teknologi Pertanian.

Budianta, Dedik. 2004. Evaluasi Pemanfaatan Limbah Cair Kelapa Pabrik Kelapa Sawit terhadap Ketersediaan Hara dan Produksi Tandan Buah Segar Kelapa Sawit. Jurnal Tanah Trop. 10 (1): 27-32.

Doli, Christian. 2015. Nilai Ekonomi Pemanfaatan Limbah Padat Kelapa Sawit di Kabupaten Bengkulu Utara (Studi Kasus di PT. Agricinal dan PT. Mitra Puding Mas). Skripsi. Bengkulu: Universitas Bengkulu.

Harris, dkk. 2013. Studi Pemanfaatan Limbah Padat dari Perkebunan Kelapa Sawit pada PLTU $6 \mathrm{~W}$ di Bangka Belitung. Jurnal Teknik Pomits. 2 (1): 73-78.

Kurniati, Elly. 2008. Pemanfaatan Cangkang Kelapa Sawit sebagai Arang Aktif. Jurnal Penelitian Ilmu Teknik Volume 8, No. 2, Desember 2008: 96-103.

Nur, Muhammad. 2013. Analisis Pemanfaatan Limbah Cair Industri Kelapa Sawit untuk Land Application. Jurnal Sains Teknologi dan Industri UIN Suska Riau Volume 10, Nomor 2.

Sarwono, Edhi. 2008. Pemanfaatan Janjang Kosong sebagai Substitusi Pupuk Tanaman Kelapa Sawit. Jurnal APLIKA. 8 (1) : 19-23.

Sugiyono. 2008. Metode Penelitian Kuantitatif Kualitatif dan R\&D. Bandung: Alfabeta.

Suhartana. 2006. Pemanfaatan Tempurung Kelapa sebagai Bahan Baku Arang Aktif dan Aplikasinya untuk Penjernihan Air Sumur di Desa Belor Kecamatan Ngaringan Kabupaten Grobogan. Jurnal Fisika. 9 (3): 154-159. Sunyoto, Danang. 2013. Ekonomi Manajerial: Konsep Terapan Bisnis. Yogyakarta: CAPS.

Widjaja, Ermin. dkk. 2002. Potensi Limbah Solid Kelapa Sawit sebagai Pakan Sapi di Kabupaten Kotawaringain Barat, Kalimantan Tengah. Jurnal PPTP. 5 (2): 44-53. 
ISSN: 1412-8837

Wulandari, I Gusti Ayu Made. 2011. Analisis Ekonomi pengembangan Bendungan Poh Santen di Desa Poh Santen Kecamatan Mendoyo Kabupaten Jembrana. Thesis. Bali: Universitas Udayana.

202 | Shofaul Afifah, Sriyoto, dan Bambang S., Analisis Nilai Ekonomi Limbah... 